\title{
COUNTEREXAMPLES TO A MATRIX EXPONENTIAL INEQUALITY
}

\author{
WASIN SO
}

Abstract. Counterexamples are constructed for a matrix exponential inequality conjectured in [Linear and Multilinear Algebra 47 (2000) 249-258].

Mathematics subject classification (2000): 15A18, 15A45.

Key words and phrases: Singular value; matrix exponential; matrix inequality.

\section{REFERENCES}

[1] R. Horn and C. Johnson, Matrix Analysis, Cambridge University Press, 1988.

[2] W. So AND R. C. ThOMPSON, Singular values of matrix exponentials, Linear and Multilinear Algebra 47 (2000) 249-258. 